\title{
Global Warming Prediction Model of Fish Migration Based on ArcGIS
}

\author{
Zhang Yipeng, Ning Dichao, He Wentao \\ College of Science, Lanzhou University of Technology, Lanzhou, 730050
}

\begin{abstract}
Rising global ocean temperatures will disrupt the livelihoods of people who depend on fishing for marine crops. Therefore, we propose fishery migration prediction models to solve the problem. We considered the effects of seawater temperature and salinity, and constructed a fish school migration prediction model based on ArcGIS. On this basis, a thermodynamic map of fish school distribution were made using ArcGIS software and kriging interpolation and nuclear density analysis. Moreover, linear interpolation and fitting are used to obtain the relationship between the annual fish movement distance and the year to predict the fish migration routes in the next 50 years.
\end{abstract}

Keywords: Rising global ocean temperatures, Fish migration prediction model, ArcGIS, Fitting

\section{Introduction}

As a result of human activity, global warming is causing the temperature of the world's oceans to continue to rise. Global ocean temperatures have been rising significantly, so this has created a number of problems, including ecological impacts, the relocation of some traditional fisheries, increased competition among fisheries, and impacts on biological reproduction. It is necessary to study the effects of ocean temperatures on fisheries, which account for a considerable proportion in some countries and affect people's livelihoods. In order to study the influence of the above problems, we consider many factors and establish several models to discuss the benefits of the problems.

Do a good analysis of the problems, determine a good research direction.

Now, we need to design a mathematical model for the fisheries management association to account for the migration of fish stocks. Our team's modeling objectives are: Predict where herring and mackerel schools will migrate in the next 50 years. 


\section{Model Establishment}

\subsection{Fish migration prediction model}

\subsubsection{The location of future schools of fish}

We collected data on the variation of ocean temperature, salinity and water pressure in the Scottish waters in recent decades from the official websites of NASA ${ }^{[1]}$ and ICES. We first processed the data, detected the data with wavelet outliers, and screened out reasonable data.1. Factors affecting the habitat change of shoals.

The factors affecting fish habitat change. By collating the data of some survey points in the waters around Scotland, we can obtain the data of various points in the waters around Scotland from 1970 to $2018^{[2]}$.

Due to Marine yearbook* from Scotland, Scottish herring and mackerel fishing period for a year the autumn of the year as of the spring, so in these data, we select the annual march to 9 months of points measured data for the analysis of ocean temperature and salinity, at the same time in order to the accuracy of the results we select each year in the same month for analysis and prediction. Some data are shown in table 1 below:

Table 1: Partial measurement point data

\begin{tabular}{|c|c|c|c|c|}
\hline Year & Latitude & Longitude & TRMP & PSAL \\
\hline 1970 & 58.85 & -18.80 & 10.16 & 35.371 \\
\hline 1980 & 57.8333 & -1.833 & 5.96 & 34.494 \\
\hline 1990 & 53.0533 & 0.4067 & 10.8 & 34.32 \\
\hline 2000 & 59.9573 & -5.4873 & 10.38 & 35.293 \\
\hline 2010 & 58.3615 & 0.454 & 8.39 & 35.275 \\
\hline 2018 & 61.2335 & -2.6638 & 9.43 & 34.91 \\
\hline
\end{tabular}

The kriging interpolation algorithm in ArcGIS software ${ }^{[3]}$ be used to draw the gradient map according to the data. Kriging interpolation ${ }^{[4]}$ is a method to estimate unknown functions by weighted average. The derivation is:

$$
\begin{gathered}
\hat{Y}\left(s_{o}\right)=\mu+\sum_{i=1}^{n} a_{i} s_{i}+\varepsilon \\
\max _{a}\left[Y\left(s_{o}\right)-\hat{Y}\left(s_{o}\right)\right]
\end{gathered}
$$

The estimation of variables in random fields is expressed as a linear system with random errors $\varepsilon$, where $s_{o}$ is the unknown point, where $\left\{s_{1}, . ., s_{n}\right\}$ is the sample of random field and is the weight coefficient, which is often referred to as kriging weight. From the variance definition, we know that when the estimated value and the mathematical expectation of the real value are the same, the variance of the two is the smallest:

$$
E\left[Y\left(s_{o}\right)\right]=E\left[\hat{Y}\left(s_{o}\right)\right]
$$

By using kriging interpolation and combining the temperature and salinity data of the selected waters around Scotland from September to march from 1970 to 2018, we can draw an is gradient map of sea water temperature and salinity. 


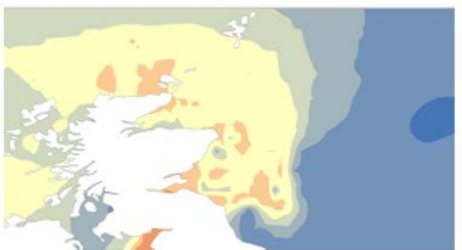

1970

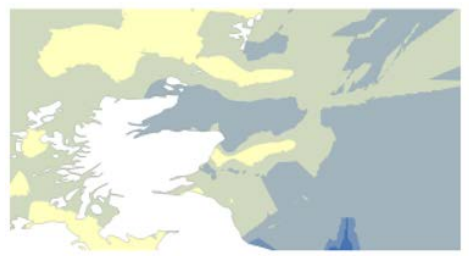

2000

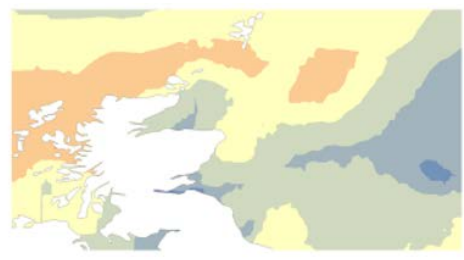

1990

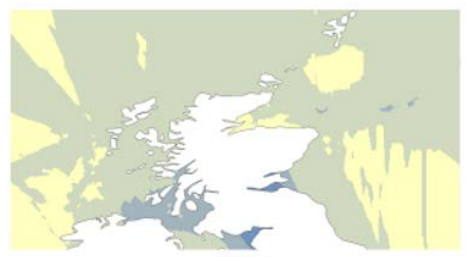

2018

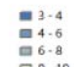

믕.8

맘 $10 \cdot 12$

‥ $12 \cdot 16$

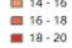

Figure 1. Flowchart of solution

From the figure above, the water color has gradually increased from light to deep, and the water temperature around Scotland has increased year by year from 1970 to 2018. The salinity of the water gradually increases from the color of the water to the shallower water, and the salinity of the water around Scotland remained basically unchanged from 1970 to 2018 .

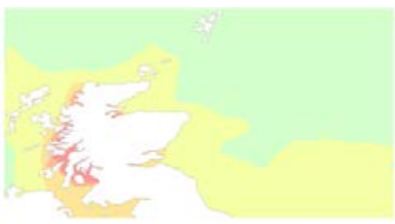

1970

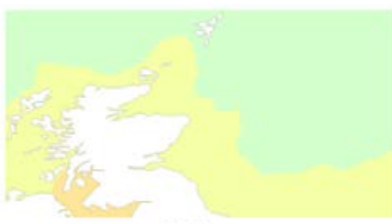

2000

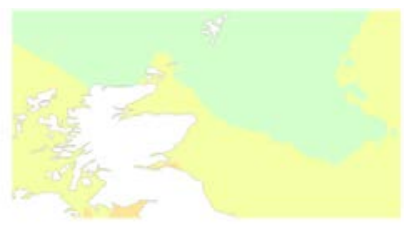

1990

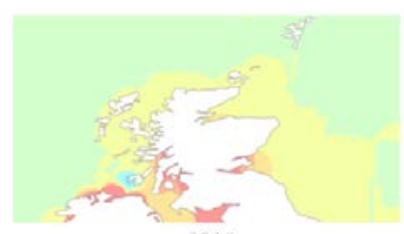

2018

Figure 2. Partial concentration of seawater
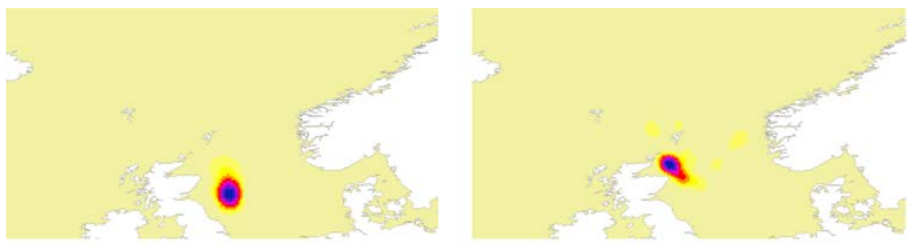

1970

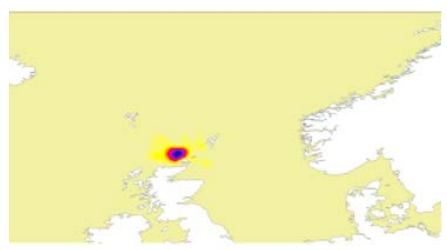

2000

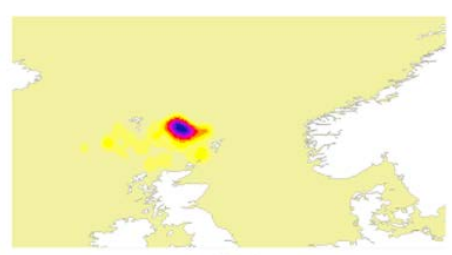

2018 
Figure 3. Fish density heat map

\subsection{Distribution density of fish}

Using the AHP method ${ }^{[5]}$, we can estimate the approximate distribution density of fish every year from the annual temperature and salinity maps and data. We know from the Scottish fisheries sensitivity report in the Scottish Marine and freshwater science report that herring and mackerel change their habitats in response to factors such as ocean temperature, salinity, and depth.

Among them, ocean temperature is the main influencing factor, ocean salinity is the secondary influencing factor, and ocean depth has little influence on it. Therefore, we can use AHP method to subjectively determine the proportion of each influencing factor as follows: the ratio of the weight coefficient of temperature to depth is five to one, and the ratio of the weight coefficient of salinity to depth is three to one, so as to write the judgment matrix as follows:

$$
A=\left[\begin{array}{llllll}
1 & 3 & 5 ; 0.33 & 1 & 3 ; 0.2 & 0.33,1
\end{array}\right]
$$

This judgment matrix is checked by the program, and the consistency of this matrix is acceptable, where: $\mathrm{CI}=0.0165, \mathrm{CR}=0.0318$.

It was found that the optimum ocean temperature for herring and mackerel in Scotland was about 10 degrees and the optimum ocean salinity was about 35 degrees ${ }^{[6]}$. Therefore, based on the judgment matrix in the AHP method and the seawater temperature distribution and salinity distribution in the surrounding waters of Scotland over the years, the annual fish density thermal map can be obtained by using the kernel density analysis method ${ }^{[7]}$ in ArcGIS.

\section{Conclusion}

Where, $\mathrm{r}$ is the search radius, and scale is the proportion between the distance from the center point of the grid to the point and the line object and the search radius. From the figure above, the density of fish population decreases gradually from dark color to pre-shoal density. The changing trend path is roughly shown in the figure below:

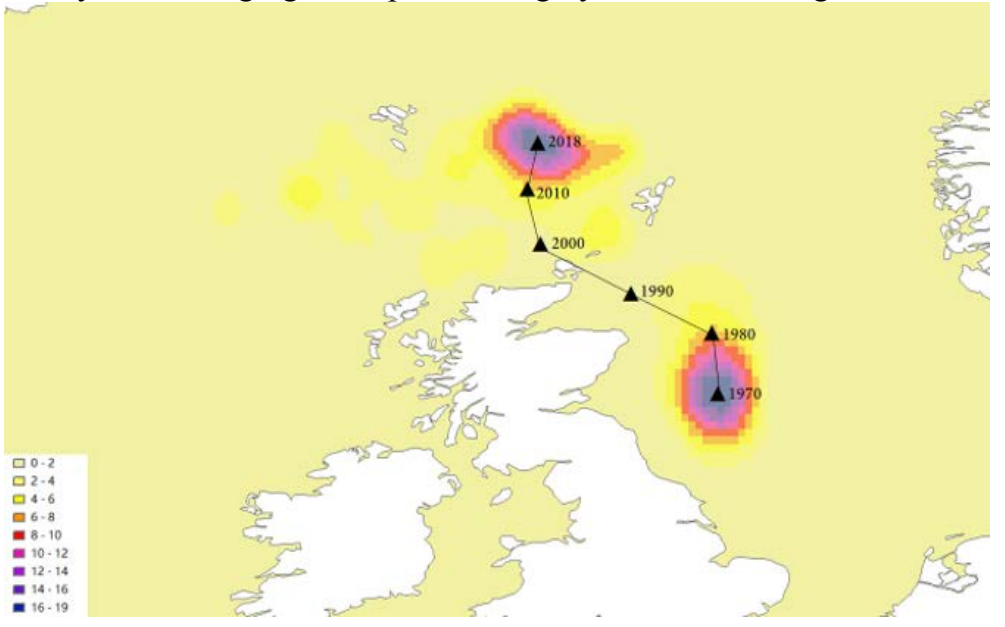

Figure 4. Patterns of changing trends in shoal habitat

According to figure 4, the changing trend path is shown in the following table: 
Table 2: A chart of the migration of fish

\begin{tabular}{|c|c|c|}
\hline Starting time & Time & The cumulative distance \\
\hline 1970 & 1970 & 0 \\
\hline 1970 & 1980 & 1.258132 \\
\hline 1970 & 1990 & 3.199772 \\
\hline 1970 & 2000 & 5.421817 \\
\hline 1970 & 2010 & 6.615737 \\
\hline 1970 & 2020 & 7.577105 \\
\hline
\end{tabular}

Where $\mathrm{F}$ is the distance between the year and the starting point (1970). Therefore, we assume that the shoal keeps moving northward, and combined with the distance, we can predict the possible locations of the two types of Scottish shoal in the next 50 years, as shown below:

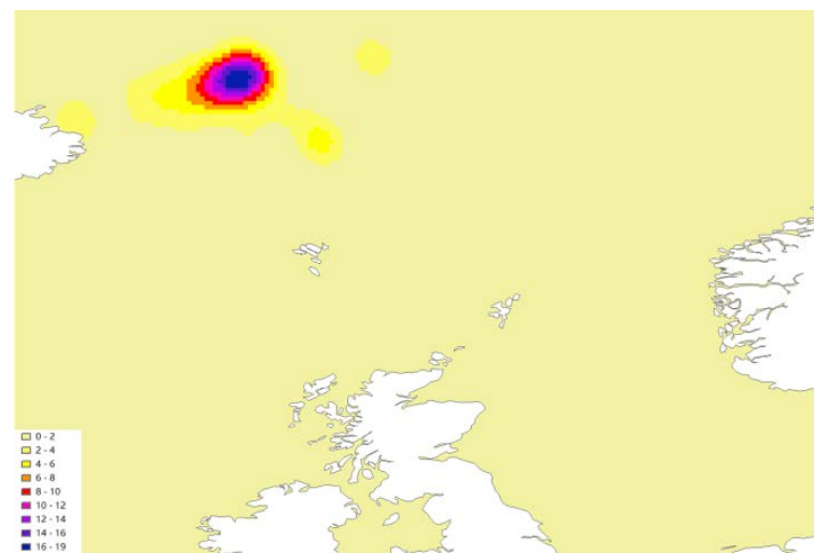

Figure 5. Projected fish population density in 2070

\section{References}

1. NASA. Ocean temperature data for Scotland [DB/OL]. [2019]. https://oceancolor.gsfc.nasa.gov/.

2. Scottish Government. Scottish Marine Freshwater Science [M].10.Scottish Government, 2014.

3. Scottish Government. Scottish Sea Fisheries Statistics 2016. 2017.

4. Tang Guoan, Yang Xin. ArcGIS Experimental tutorial on spatial analysis of geographic information systems[M].2.Science Press, 2016.

5. Liu, Yi, et al. "Federated Learning in the Sky: Aerial-Ground Air Quality Sensing Framework with UAV Swarms." IEEE Internet of Things Journal (2020).

6. Li Junxiao, li Chaokui, Yin Zhihui. Kriging interpolation method based on ArcGIS and its application [J]. Bulletin of surveying and mapping, 2013(09):87-97.

7. Chang Jian 'e, JIANG Tai Li. Information and Management Engineering Edition, 2007(1):153-156.

8. V.M. Trenkela, G. Huseb, B.R. MacKenziec, P. Alvarez, H. Arrizabalaga, M. Castonguay, N. Goñi, F. Grégoire, H. Hátún, T. Jansen, J.A. Jacobsen, P. Lehodey, M. 
Lutcavage, P. Mariani, G.D. Melvin, J.D. Neilson, L. Nottestad, G.J. Óskarsson, M.R. Payne, D.E. Richardson, I. Senina, D.C. Speirs. Comparative ecology of widely distributed pelagic fish species in the North Atlantic: Implications for modelling climate and fisheries impacts [J]. Progress in Oceanography, 2014(129)219-243.

9. Hu Kang, Hao Rong, Cheng Chen, Wang Chongmin. Detection of foodborne disease hotspots based on nuclear density analysis [J]. Chinese journal of health information management, 2019, 16(01):109-112.

10. Wu, Yi, et al. "Dominant Data Set Selection Algorithms for Electricity Consumption Time-Series Data Analysis Based on Affine Transformation." IEEE Internet of Things Journal 7.5 (2019): 4347-4360.

11. Zhao, Ziming, Jialin Wang, and Yi Liu. "User electricity behavior analysis based on K-means plus clustering algorithm." 2017 International Conference on Computer Technology, Electronics and Communication (ICCTEC). IEEE, 2017. 